\title{
DEC vs. DEC-compatible hardware
}

\author{
DORIS AARONSON \\ New York University, New York, New York 10003
}

\begin{abstract}
In recent years, users of Digital Equipment Corporation (DEC) computers have been offered compatible products manufactured by other companies. This paper reviews the results of a survey concerning the purchase and use of non-DEC products; comments concerning advantages or disadvantages of buying DEC vs. non-DEC products are noted.
\end{abstract}

For the past 5 years, researchers who use DEC computer equipment in their laboratories have been buying increasingly more of their equipment from vendors other than DEC. In fact, we now see numerous advertisements in the trade journals from non-DEC vendors that explicitly call our attention to the fact that their products are "DEC compatible" or are substitutes for components in specific DEC machines, such as the PDP-11 series. To obtain more information on this trend, I took a survey of our DEC user group.

Considerations include the following: What components do our users buy from DEC or non-DEC companies, and why do they decide on a particular vendor? Of the 100 questionnaires mailed out, 25 users replied. Their responses for four classes of hardware are summarized in four tables. For each of the tables, the leftmost column lists the most frequent components purchased by our computer users. The next three columns contain information on where the items were obtained. Items were (1) made in the local laboratory electronics shops, (2) purchased from a non-DEC vendor, or (3) bought from DEC. The last column contains the names of specific non-DEC vendors from which the users bought their components. Note that the numbers in each row may add up to less than 25 , as not all users may have a particular component on their machines (e.g., printers). Also, the numbers may sum to more than 25 , since the users may have both DEC and non-DEC equipment of that type (e.g., extra memory).

First, consider the category "Central Machine," in Table 1. Data are listed under the subtopics "Main CPU," "Memory," and maintenance "Service," as these are items common and central to every computer. The data in the first row include the following CPUs: six PDP-8s, four PDP-12s, two PDP-9s, one PDP-15, and 12 PDP-11s. The first row shows that two DEC CPUs were not bought from DEC, but rather from usedcomputer companies. Other companies now exist, such as Plessey, that manufacture total systems based on DEC-made CPUs that are compatible with other DEC

This report was supported in part by Grant MH-16,496 from NIMH to New York University. I thank Misha Pavel for helpful comments on this report. hardware and software. These were not listed by any of our respondents, although I personally know of some psychology computer users who have them in their laboratories. The second row shows that all but two respondents purchased extra memory, about half of these from DEC and half from non-DEC vendors. Most users ordered $8 \mathrm{~K}$ or $16 \mathrm{~K}$ words of memory with their initial machine purchases and now have 32K. Asterisks in this table indicate non-DEC vendors used by more than one respondent; Fabri-Tek, Monolithic, and Plessey have multiple purchases of memory from the survey respondents. In the third row of Table 1 , under the row labeled "Service," only the 11 users who have regular annual service contracts with DEC on their main CPUs and some major peripherals, usually disks and tape drives, are listed as DEC. Many of these do not have contract coverage on several minor peripherals. Alternatively, many of the 11 users listed as doing their own repair service also use DEC from time to time on a "per-call" basis. Finally, note that three users maintain annual contracts with non-DEC companies.

In the second category, "Interface," in Table 2, low-speed and DMA interfaces are listed, as well as some components that are closely related to those types of interface, and that are often part of a larger interface system to yet more peripheral devices. These additional interface components are digital $\mathrm{I} / \mathrm{O}$, timers, and $\mathrm{A} / \mathrm{D}$ and D/A conversion circuitry. For this broad interface category, if we combine items made in-house with those purchased from non-DEC vendors, these sources together account for $44 \%$ of the market for interface on DEC laboratory machines. If we sum the tallies over the particular subitems, the number made in-house just about equals that purchased from non-DEC vendors. This high frequency of in-house equipment suggests that psychologists have become more educated and more sophisticated about engineering and computer technology over the past 5 years. Or, perhaps, they have extracted more salary funds from deans and grants to employ competent engineers as a part of research support staffs. DEC's lead, with $56 \%$ of the market in these interface items, comes primarily from sales of low-speed interface and timers. However, MDB is rapidly gaining on DEC in the general interface area. 
Table 1

Central Machine

\begin{tabular}{|c|c|c|c|c|}
\hline Computer Component & Homemade & Non-DEC & DEC & Names of Non-DEC Vendors \\
\hline Main CPU & 0 & 2 & 23 & Newman, Terak \\
\hline Memory & 0 & 15 & 13 & $\begin{array}{l}\text { Fabri-Tek, }{ }^{*} \text { Monolithic, }{ }^{*} \text { Plessey, } \\
\text { Cambridge, Dataram, Keronix, Galaxy, } \\
\text { Charles River, CES }\end{array}$ \\
\hline Service & 11 & 3 & 11 & GE, ICE, Digital Services \& Development \\
\hline
\end{tabular}

Note-Data $=$ number of users who bought components from each of three sources.

*Non-DEC vendors used by more than one respondent.

Table 2

Interface

\begin{tabular}{lcccl}
\hline Computer Component & Homemade & Non-DEC & DEC & \multicolumn{1}{c}{ Names of Non-DEC Vendors } \\
\hline Low-Speed Interface & 2 & 8 & 13 & MDB, * Able Computer,* Data 100, ICR \\
DMA & 1 & 1 & 1 & MDB* \\
Digital I/O & 6 & 5 & 7 & MDB, * SKED, ICR, La Jolla Electronics \\
A/D & 3 & 2 & 7 & Cambridge, La Jolla Electronics \\
D/A & 6 & 2 & 7 & ADAC, Cambridge, La Jolla Electronics \\
Timers & 2 & 3 & 17 & Cambridge, Heath, Digital Pathway \\
\hline
\end{tabular}

Note-Data $=$ number of users who bought components from each of three sources.

*Non-DEC vendors used by more than one respondent.

Table 3 contains mass storage devices, including disks, magnetic tapes, and, for users with antique PDP-8s and PDP-12s, the high-speed paper-tape reader/punches. DEC leads in this general area, controlling two-thirds of the market. Non-DEC products in this area are distributed over a wide variety of companies. Plessey is a leading non-DEC vendor, selling disks compatible with the PDP-11 series computer. Obviously, no in house-built mass storage devices are reported.

Table 4 shows the miscellaneous peripheral devices, including terminals, graphics, printers, plotters, and phone modems. There is some confusion among the rows labeled "Terminals," "Graphics," and "Printers." Users did not list console terminals as separate components, since they were supplied with the original machines. (The console terminals are by and large DEC products.) Different researchers may use the same device for different purposes and thus list it under different columns. As a result, DECwriters are sometimes listed as terminals and sometimes as printers, particularly the new high-speed versions. Video terminals are sometimes listed as terminals and sometimes as graphics, for example, when the researchers use them primarily for stimulus displays. The summary of these data keeps these three types of components in exactly the same rows as the users listed them. For the peripheral devices, DEC controls just over half of the market, 53\%. DEC leads with terminals and printers, but non-DEC vendors sell more plotters, graphics, and phone modems.

Why do psychology researchers buy DEC-compatible hardware from DEC or from non-DEC vendors? The reasons appear to be related to the hardware and to an intangible factor having to do with service and customer relations.

Under the hardware category, the first and most frequent reason given for non-DEC purchases of every category of components was cost; non-DEC equipment is less expensive. New equipment, presumably equal to or better than DEC's, was purchased from $25 \%$ to as much as $50 \%$ less than DEC prices. Also, used DEC computers and used components were purchased from the American and Newman companies with customer satisfaction in the quality of the used equipment. A second reason was that some particular components were reported to be of higher quality than DEC products. These included the reliability of Monolithic, Fabri-Tek, and Plessey memory; the speed, capacity, and compactness of disks from several firms; and the

Table 3

Mass Storage Devices

\begin{tabular}{ccccc}
\hline Computer Component & Homemade & Non-DEC & DEC & Names of Non-DEC Vendors \\
\hline Hard Disk & 0 & 7 & 12 & Plessey, * EM\&M, Computer Labs \\
Floppy Disk & 0 & 3 & 3 & Xebec, AED, Charles River \\
DEC-Tape & 0 & 2 & 10 & American Used, Newman Used \\
Mag Tape & 0 & 4 & 3 & Cipher, Digi Data, Pertec, PEC \\
Paper Tape & 0 & 1 & 8 & Teletype \\
\hline
\end{tabular}

Note-Data $=$ number of users who bought components from each of three sources.

*Non-DEC vendors used by more than one respondent. 
Table 4

Miscellaneous Peripheral Devices

\begin{tabular}{lcccl}
\hline Computer Component & Homemade & Non-DEC & DEC & Names of Non-DEC Vendors \\
\hline Terminal & 0 & 9 & 15 & Lier-Siegler, * Hazeltine, * ADDS, ${ }^{*}$ TTY, Lanpar, Ann Arbor \\
Graphics & 1 & 7 & 6 & Tektronix, ${ }^{*}$ Hewlett-Packard, Matrox, ADDS, CCI \\
Plotter & 0 & 2 & 0 & Hewlett-Packard, MFE \\
Printer & 0 & 3 & 8 & Houston Instrument, Printronix, TTY \\
Phone Modem & 0 & 6 & 2 & Gandolf, Comdata, Omnitec, Bell \\
\hline
\end{tabular}

Note-Data $=$ number of users who bought components from each of three sources.

*Non-DEC vendors used by more than one respondent.

picture quality of several visual display terminals. A third reason involved particular design features for specific research needs, features not made by DEC at the time of purchase. These included the structural flexibility of MDB interface, more than the usual accuracy and reliability of $A / D$ and $D / A$ circuitry, floppy disks with high-speed DMA interfaces, batterypowered components for portable laboratories, and graphics terminals with special features needed for vision research. A fourth reason was company willingness to make custom design modification or even entire peripheral components. La Jolla Electronics and Cambridge Electronics were cited several times on this score. A final reason was compatibility with non-DEC hardware at particular university computer centers. This was cited for several magnetic tape purchases and for Gandolf terminals (for $25 \%$ of the laboratories).

Under the less tangible category of purchasing criteria, the first reason cited for dealing with non-DEC vendors was delivery speed, both on the initial purchase and on replacement, and swapping procedures for repair service. Companies that handle only a few components, rather than entire systems, carry a large stock of those few items, often with a 2 -week delivery time, as opposed to DEC's standard of 3 months (which often turns out to be at least 6 months). A second reason has to do with the personal aspects of customer relations. Smaller companies often "try harder," as the saying goes. Ten years ago, when DEC was smaller, the company apparently cared about each customer. For various reasons, this relationship has changed. Further, the smaller non-DEC companies are often local firms based in the particular home town of the researcher. This provides a strong social basis to maintain good business relationships with customers. A final reason is that some maintenance costs have been reduced on particular components: first, for home-made components; second, on larger systems, if total service contracts are bought from other firms, such as G.E. The potential purchaser of non-DEC components for a DEC machine should refer to an excellent article by Palya (1978) on $\mathrm{DEC}$-compatible products, listing non-DEC vendors and engineering problems to watch out for.
DEC computer owners, in spite of all these reasons for dealing with vendors other than DEC, still make the vast majority of their purchases, especially the more expensive components, from DEC. Start by considering the hardware-based reasons. The most frequently expressed reason for going with DEC was "compatibility." This is a three-pronged reason: Users want the entire system to be DEC, so that peripherals and CPU are compatible in an engineering sense. Some users want the system to be compatible with other computer systems in their departments (i.e., to have a maximum of identical components) to optimize maintenance procedures and intercomputer communication. Finally, users want their systems to be compatible (i.e., again, almost identical) with those of outside laboratories, in order to share device-specific software. Second, DEC was praised on its hardware, especially for the high quality and reliability of components, particularly CPUs, DECwriters, and disks. Finally, DEC users complimented the company's production of total systems that meet the needs of real-time laboratory research.

On the nontangible side, several laboratories reported going almost $100 \% \mathrm{DEC}$ because it is simple. That is, the computer users do not have to become involved in the technical engineering considerations required in trying to match components from different vendors. Several laboratories purchased fully DEC systems because of the high-quality systems software support provided. As much as the user group members complain about DEC field service, a number of laboratories wanted fully DEC systems in order to have a single company providing maintenance service for the entire system. Finally, several users were impressed by DEC's customer relations, responding "DEC is expensive, but worth it." DEC personnel have particularly impressed our users in several Canadian provinces and in the New England area.

At this point, I would like to add some other pro-DEC comments made by members of the National Conference on the Use of On-Line Computers in Psychology during the past 5 years. The first four might be considered "back-handed compliments." I have heard 
far worse horror stories about non-DEC vendors than about DEC regarding poor-quality and unreliable hardware, regarding late deliveries and companies who did not produce the specifications promised, regarding lack of documentation for circuitry and operating procedures, and finally, regarding small companies that went bankrupt, were sold by their parent companies, or discontinued support for past product lines. A final note of recommendation for DEC is that its more expensive hardware provides the financial support to give psychologists some of the most creative hardware research and development efforts, including the PDP-1 and the PDP-8, and more recently, the PDP-11 series of computers.

\section{REFERENCE}

Palya, W. L. A source handbook for Digital Equipment Corporation LSI-11-compatible products. Behavior Research Methods \& Instrumentation, 1978, 10, 488-509. 